PERSPECTIVE

\title{
Vascular endothelial growth factor biology: clinical implications for ocular treatments
}

\author{
R B Bhisitkul
}

Br J Ophthalmol 2006;90:1542-1547. doi: 10.1136/bjo.2006.098426

Decades of research on vascular endothelial growth factor (VEGF) have reached fruition with the recent development of intravitreal anti-VEGF treatments for exudative agerelated macular degeneration. VEGF is a critical regulator of angiogenesis and vascular permeability with diverse roles, both pathological and physiological, during development and adulthood. The aim of this article is to review aspects of VEGF biology that may be relevant to the clinical use of anti-VEGF agents in ophthalmology: molecular characteristics and isoforms of VEGF; its roles in vasculogenesis, vascular maintenance and angiogenesis; systemic effects of VEGF inhibition; and properties of current anti-VEGF agents.

Correspondence to: R B Bhisitkul, Department of Ophthalmology, Beckman Vision Center, University of California San Francisco, 10 Koret Way, K301, San

Francisco, CA 94143,

USA; BhisitkulR@vision. ucsf.edu

Accepted 19 June 2006
$\mathrm{T}$ he advent of anti-vascular endothelial growth factor (VEGF) treatments marks a major advancement in the treatment of angiogenic eye disease, first with the US Food and Drug Administration approval of pegaptanib sodium (Macugen; OSI/Eyetech Pharmaceuticals, New York, USA) in 2004, followed by recent positive clinical trial results for ranibizumab (Lucentis; Genentech) and the growing off-label use of intravitreal (ITV) bevacizumab (Avastin; Genentech, San Francisco, USA). Although it is clear from randomised clinical trials that ITV antiVEGF treatments will have a fundamental effect for patients with neovascular age-related macular degeneration (AMD), ophthalmologists embarking on the use of these drugs are still faced with some unresolved issues. These include determining the ideal regimen and duration of treatment, the potential of combination treatments and safety concerns with long-term VEGF inhibition. Although some of these issues may be tackled by expanding clinical experience, a review of the relevant VEGF science can inform the clinical application of these novel treatments. The aim of this review is to consider the biology of the VEGF gene family and VEGF-A isoforms, the physiological role of VEGF-A in development and adulthood, the role of VEGF-A in the pathogenesis of ocular diseases, the differential therapeutic mechanisms of current and upcoming antiVEGF agents and the safety considerations involved in VEGF inhibition.

\section{VEGF BIOLOGY}

VEGF is a homodimeric glycoprotein and is a growth factor specific for endothelial cells. ${ }^{1}$ It is a critical regulator of vasculogenesis and angiogenesis, as well as a potent inducer of vascular permeability. $^{2-4}$ Additional VEGF functions under study include retinal leukostasis and neuroprotection..$^{23-7}$ Three receptor tyrosine kinases have been identified for VEGF: VEGF receptor (VEGFR) l (fms-like tyrosine kinase-1) has both positive and negative angiogenic effects; VEGFR2 (fetal liver kinase-1 and kinase insert domain-containing receptor) is the primary mediator of the mitogenic, angiogenic and vascular permeability effects of VEGF-A; and VEGFR3 mediates the angiogenic effects on lymphatic vessels. ${ }^{18}$ The pathological functions of VEGF-A have received the most attention, culminating in the development of a new class of drugs for neovascular eye disease and cancers. But VEGF-A and its receptors are also present in tissues and organ systems in normal adults, underlining the physiological role of VEGF-A.

\section{VEGF gene family}

The VEGF gene family consists of VEGF-A, VEGF-B, VEGF-C, VEGF-D and placental growth factor (PlGF), which have different binding affinities for the three VEGF receptors.9 ${ }^{10}$ VEGF-A is the best studied, has been most strongly associated with angiogenesis, and is the target of most current anti-VEGF treatments. ${ }^{11} 12$ VEGF-A signals through two receptor tyrosine kinases, VEGFRl and VEGFR2, and is the only member of the VEGF gene family found to be induced by hypoxia. ${ }^{13}$ VEGF-B selectively binds VEGFRl and has a role in the regulation of extracellular matrix degradation, cell adhesion and migration. ${ }^{9}$ Both VEGF-C and VEGF-D bind VEGFR2 and VEGFR3 and regulate lymphangiogenesis, and VEGF-C may also be involved in wound healing..$^{10} 14$ PlGF selectively binds VEGFR $1^{9}$ and is the most abundantly expressed VEGF family member in endothelial cells. ${ }^{13}$ PlGF may potentiate VEGF-A-induced endothelial cell proliferation, ${ }^{13}$ but on its own PlGF exerts only weak mitogenicity. ${ }^{13}$

\section{VEGF-A isoforms}

Nine major VEGF-A isoforms have been identified in humans: VEGF ${ }_{121}, V \mathrm{VGF}_{145}, \mathrm{VEGF}_{148}$, $\operatorname{VEGF}_{162}, V \mathrm{VEF}_{165}, V \mathrm{VEF}_{165 \mathrm{~b}}$ (an endogenous

Abbreviations: $A M D$, age-related macular degeneration; CNV, choroidal neovascularisation; CRC colorectal cancer; ECM extracellular matrix, ; ITV intravitreal; $m A B$, monoclonal antibody; PIGF, placental growth factor; RPE, retinal pigment epithelium; VEGF, vascular endothelial growth factor; VEGFR, VEGF receptor; VISION, VEGF Inhibition Study in Ocular Neovascularization. 
inhibitory isoform that binds to VEGFR2 with similar affinity to $\mathrm{VEGF}_{165}$ but does not activate it), $\mathrm{VEGF}_{183}, \mathrm{VEGF}_{189}$, and VEGF $_{206}{ }^{15}$ These isoforms are produced by alternative exon splicing of the human VEGF-A gene on chromosome 6p21.3. ${ }^{15} \mathrm{VEGF}_{165}$ and longer isoforms consist of two domains: a VEGF receptor-binding domain that is present in all VEGF-A isoforms and a heparin-binding domain that is absent in the shorter diffusible isoforms. Longer isoforms, such as $\mathrm{VEGF}_{189}$ and $\mathrm{VEGF}_{206}$, bind to the extracellular matrix (ECM) via the heparin-binding domain. ${ }^{1}{ }^{16}$ The VEGF $_{165}$ isoform is intermediate, and exists as both diffused and partly ECM-bound. ${ }^{17}{ }^{18}$ Studies have established that VEGF $_{165}$ is the most abundantly expressed VEGF-A isoform and has a vital role in angiogenesis. ${ }^{19}{ }^{20}$ In addition, one study has found that $V_{E G F} 121$, although less abundant, is more mitogenic than VEGF $_{165}$ or VEGF $189 .{ }^{21}$ All VEGF-A isoforms except $V_{E G F} F_{121}$ contain a plasmin cleavage site and theoretically may be cleaved by plasmin to generate the smaller VEGF 110 form. ${ }^{15}{ }^{19} \mathrm{VEGF}_{110}$ can stimulate endothelial cell growth and induce vascular permeability in the Miles assay $^{17}$; however, its mitogenic potency is less than that of VEGF $_{165} .^{22}$

$\mathrm{VEGF}_{121}, \mathrm{VEGF}_{165}, \mathrm{VEGF}_{183}$ and $\mathrm{VEGF}_{189}$ are distributed widely in tissue, with VEGF 165 expression the most abundant. In contrast, $\mathrm{VEGF}_{145}$ and $\mathrm{VEGF}_{206}$ are less abundant. In mice the VEGF-A gene is highly conserved, with three splice variants, $V_{E G F}{ }_{120}, V_{E G F} 164$ and $V_{E G F}$, equivalent to the human $V E_{121}, V_{16 G F} 165$ and $V_{E G F} 189$ isoforms, respectively. ${ }^{23}$

\section{VEGF-A in vasculogenesis}

Vascular formation can be defined in two distinct categories: vasculogenesis and angiogenesis. Vasculogenesis is the process of de novo blood vessel formation during embryogenesis, ${ }^{24}$ which begins with the differentiation, proliferation and migration of haemangiogenic stem cells under the possible influence of VEGF-A and PlGF. ${ }^{25}$ VEGF-A may also participate in endothelial cell survival and in capillary regression via synchronous apoptosis. ${ }^{26}$

Angiogenesis, which can occur in adulthood, is the process of neovascularisation from established blood vessels. Angiogenesis occurs in response to a variety of pathological stimuli including ischaemia, inflammation, wound healing and tumour formation. Angiogenesis can also be integral to tissue homoeostasis and normal processes such as the growth and maintenance of the ovarian follicle and corpus luteum during reproductive life in women. ${ }^{27}$ Thus, angiogenesis in adulthood can have both detrimental effects, such as neovascular AMD, rheumatoid arthritis and cancer, ${ }^{12}$ and beneficial effects, such as cardiac remodelling and wound healing.

VEGF-A is integral to blood vessel formation during both vasculogenesis and angiogenesis, but its role differs in development versus adulthood (fig 1). For instance, in developing mice, newly formed vessels require VEGF-A to persist through the fourth postnatal week, but after that time the vessels stabilise and no longer depend on VEGF-A for maintenance. ${ }^{28}$ VEGF deficiency is lethal during embryogenesis. ${ }^{11}$ Postnatal inhibition of the VEGF-A gene via conditional knockout technology increases mortality. ${ }^{28}$ Data from selective VEGF-A isoform knockout mice suggest that the absence of $\mathrm{VEGF}_{164}$ and $\mathrm{VEGF}_{188}$ results in a variety of vascular defects, including abnormal pulmonary vascular development. ${ }^{23}$

\section{VEGF-A in ocular development}

During ocular development, vasculogenesis occurs firstly in the choroid and hyaloid systems, where VEGF-A may have a role. VEGF-A expression has been implicated in the abnormal persistence of the hyaloid vasculature in a mouse model of persistent fetal vasculature. ${ }^{29}$ In VEGF ${ }^{\mathrm{rpe}-/-}$ mice, the lack of
VEGF-A expression relegated specifically to the retinal pigment epithelium (RPE) results in failure of the choriocapillaris to form..$^{30}$ Vascularisation of the retina occurs later in embryogenesis and is not completed until the final postnatal period, ${ }^{31}$ with VEGF-A controlling vessel sprouting and migration in the postnatal retina. ${ }^{32}$ VEGF-A expressed in the neural retina is correlated temporally and spatially with normal vasculogenesis in both humans ${ }^{24}$ and rats. ${ }^{33}$ VEGF-A appears to be induced by physiological hypoxia as part of normal retinal development, and VEGF-A suppression inhibits vascular formation. ${ }^{31}$

The function of the individual VEGF-A isoforms may differ during ocular development. Mice expressing only VEGF $_{164}$ have normal retinal angiogenesis and vasculature, whereas mice expressing only $\mathrm{VEGF}_{120}$ or $\mathrm{VEGF}_{188}$ have aberrant vascular outgrowth and arterial development. ${ }^{34}$ VEGF $_{164}$ shows the greatest upregulation during rat ocular development, in the presence of VEGF $120, \mathrm{VEGF}_{164}$ and VEGF $\mathrm{V}_{188}{ }^{35}$

\section{VEGF-A in the maintenance of adult vasculature}

In addition to vasculogenesis and angiogenesis, VEGF-A may participate in the maintenance of certain vascular systems in the adult. Specific binding of VEGF-A is associated with mature vessels in various adult rat tissues, such as the heart, kidney and brain, suggesting that VEGF-A has a function in the maintenance of quiescent vascular endothelium. ${ }^{36}$ VEGFA maintains normal tracheal vasculature in adult mice, as shown by capillary loss after broad VEGF inhibition, an effect not seen with selective $V_{E G F}{ }_{164}$ inhibition. ${ }^{37}$ In addition, chronic VEGF inhibition in adult rats results in lung alveolar septal abnormalities. ${ }^{38}$

\section{VEGF-A in the maintenance of adult ocular vasculature}

Little is known of the role of VEGF-A in the maintenance of adult ocular vasculature. VEGF-A is produced by human differentiated RPE cells both in vivo and in vitro, and may be involved in the paracrine signalling between the RPE and choriocapillaris. ${ }^{39}$ In normal adult monkey and mouse eyes, the $V_{E G F} 121$ and $V E_{165}$ isoforms are most abundantly expressed in the choroid, RPE, retina and iris tissue, consistent with VEGF-A acting as a vascular survival factor in the adult eye. ${ }^{40}$ However, in adult mice treated systemically with vatalanib, a broad inhibitor of VEGF-A isoforms and platelet-derived growth factor, no effects are seen in the retinal vasculature. ${ }^{41}$ To date, clinical trials of the VEGF-A inhibitors pegaptanib and ranibizumab in humans have not shown adverse effects on normal retinal or choroidal vasculature (Rosenfeld $e t a l^{41 \mathrm{a}}$; Brown $\left.e t a l^{4 \mathrm{bb}}\right){ }^{42}$

\section{VEGF-A in ocular pathogenesis}

The central role of VEGF-A is well established in ocular neovascular diseases. ${ }^{43-46}$ In humans, high levels of VEGF-A expression are found in choroidal neovascularisation (CNV) tissue excised from patients with AMD. ${ }^{43} 47$ Intraocular VEGF-A levels correlate with blood vessel formation in patients with diabetic retinopathy and other retinal disorders. ${ }^{44} 48$

Different VEGF-A isoforms may have different functions in ocular diseases. VEGF $_{164}$ is the predominant isoform expressed at the time of maximal preretinal neovascularisation in a neonatal rat model ${ }^{35}$ and is the primary proinflammatory isoform in the retina of rats with diabetes. ${ }^{49} 50$ Levels of both $V \mathrm{VGF}_{121}$ and $\mathrm{VEGF}_{165}$ are increased in monkeys after laser-induced retinal vein occlusion. ${ }^{51}$ VEGF $_{120}$ is the main isoform expressed in mouse CNV 


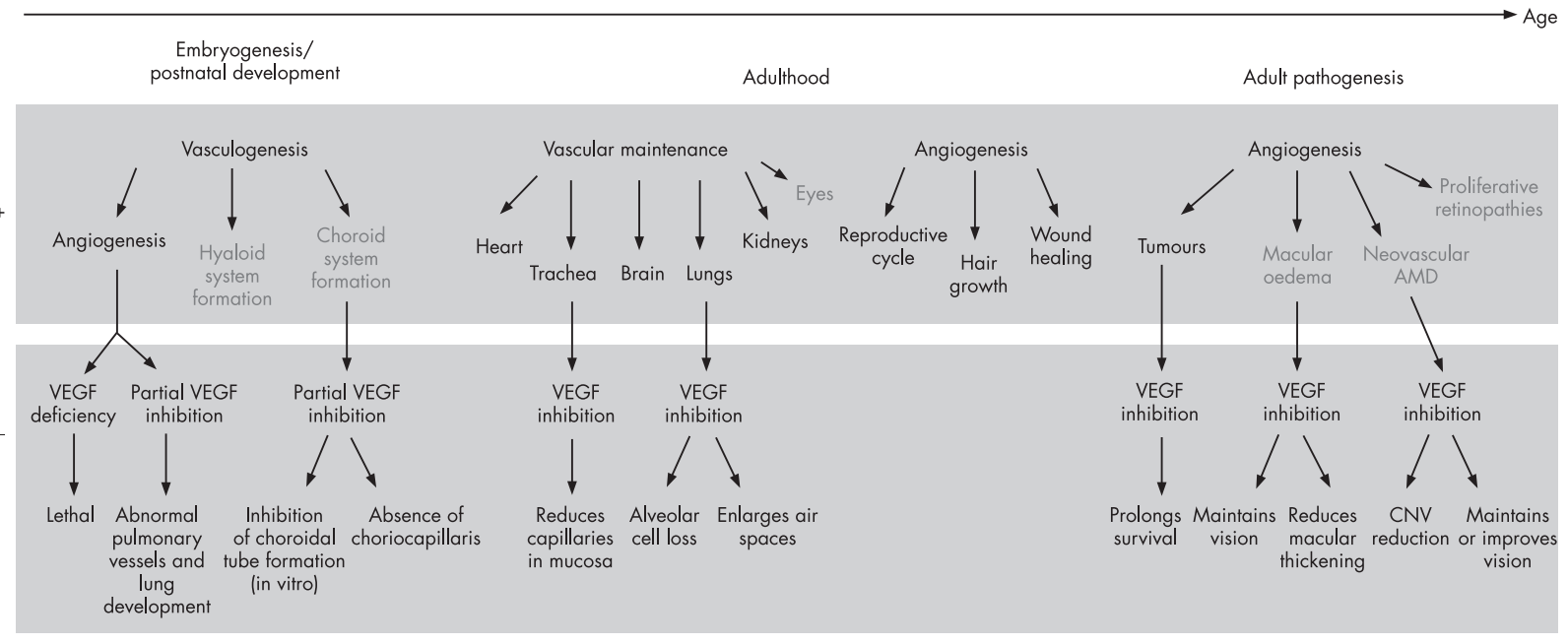

Figure 1 The role of VEGF-A and the effect of VEGF inhibition in embryogenesis, postnatal development and adulthood under normal and pathological conditions, particularly in the ocular system. AMD, age-related macular degeneration; CNV, choroidal neovascularisation; VEGF, vascular endothelial growth factor.

membranes, and inhibition of $\mathrm{VEGF}_{120}$ results in reduction of $\mathrm{CNV}$ in mice. ${ }^{43}{ }^{52}$ Both $\mathrm{VEGF}_{121}$ and $\mathrm{VEGF}_{165}$ isoforms are found in $\mathrm{CNV}$ tissue excised from patients with AMD. ${ }^{43}$

\section{VEGF-A INHIBITION}

\section{Anti-VEGF agents}

Currently available and emerging anti-VEGF treatments inhibit VEGF-A isoforms in different ways (summarised in fig 2). Pegaptanib sodium is a pegylated ribonucleic acid oligonucleotide ligand (or aptamer). It has a molecular mass of $50 \mathrm{kDa}$ and is produced synthetically to be specific for the human $\mathrm{VEGF}_{164}$ isoform, binding at its heparin-binding domain. ${ }^{16}$ Theoretically, it may bind the longer VEGF-A isoforms that also contain the heparin-binding domain.

Ranibizumab is a humanised antigen-binding fragment of a murine full-length monoclonal antibody (mAB) directed against human VEGF-A. It is produced in Escherichia coli using recombinant DNA technology and has a molecular mass of $48 \mathrm{kDa}$. Ranibizumab has been shown to inhibit $V E_{165}, V_{1 E G F}$ and $V_{12}$ aGF 110 (Lowe et al, unpublished data), and theoretically should inhibit all VEGF-A isoforms and their active degradation products, although it is technically difficult to evaluate the activity and binding of longer VEGF-A isoforms because they are sequestered in the ECM. Ranibizumab fully penetrates the retinal layers to the outer retina and inner choroid in rabbits (Gaudreault et al, unpublished data).

Bevacizumab is a $149-\mathrm{kDa}$ full-length humanised $\mathrm{mAB}$ against all VEGF-A isoforms and their active degradation products, approved as intravenous infusion in combination with chemotherapy for metastatic colorectal cancer. Off-label use of ITV bevacizumab for neovascular AMD in small retrospective studies has shown benefits for vision and reduced macular thickening. ${ }^{53}{ }^{54}$ The long-term benefits and safety of ITV bevacizumab remain to be investigated.

Several other anti-VEGF treatments are in clinical development for ophthalmology. VEGF Trap (Regeneron Pharmaceuticals, New York, USA) is a fusion protein containing the binding sites of VEGFRI and VEGFR2, which inhibits all VEGF-A isoforms and PlGF. ${ }^{55}$ Receptor tyrosine kinase inhibitors include vatalanib (PTK787; Novartis AG) and AG-013958 (Pfizer, New York, USA); these target the VEGF receptor tyrosine kinases and inhibit all VEGF-A isoforms, ${ }^{56}$ although AG-013958 also inhibits platelet-derived growth factor receptors. RNA interference-based treatments are also being explored in neovascular AMD. Cand5 (Acuity Pharmaceuticals, Philadelphia, USA) prevents the production of all VEGF-A isoforms by degrading VEGF-A mRNA. Sirna027 (Sirna Therapeutics, Boulder, USA) targets production of VEGFRI mRNA. ${ }^{57}$

\section{Therapeutic outcomes}

In the phase III VGEF Inhibition Study in Ocular Neovascularization (VISION) clinical trials, pegaptanib has been shown to be beneficial for all subtypes of $\mathrm{CNV}$ secondary to AMD. At 12 months, considerably more pegaptanib-treated patients lost $<15$ letters than patients who received sham injections $(70 \% v 55 \%)$ and more patients gained $\geqslant 3$ lines of visual acuity $(6 \% \vee 2 \%)^{42}$; benefits were maintained at 24 months. Rates of visual gain might be enhanced for treatment of small and early CNV lesions, as suggested by a subanalysis of a small group of patients from the VISION trial. $^{58}$ For patients with diabetic macular oedema, a phase II controlled clinical trial showed a considerably higher rate of visual gain of $\geqslant 10$ letters of visual acuity for pegaptanib-treated patients compared with sham-injected patients (34\% $v 10 \%)$. $^{59}$

In the phase III MARINA trial of patients with occult or minimally classic subfoveal $\mathrm{CNV}$ secondary to AMD, at month 12 considerably more ranibizumab-treated patients lost $<15$ letters than sham-injected patients (95\% v 62\%). Of the ranibizumab-treated patients, $25 \%$ and $34 \%(0.3$ and $0.5 \mathrm{mg}$, respectively) gained $\geqslant 15$ letters compared with $5 \%$ of sham-injected patients, a significant difference (Rosenfeld et $\left.a l^{11 a}\right)$. In the phase III ANCHOR trial of patients with predominantly classic subfoveal CNV secondary to AMD, 94\% and $96 \%$ of ranibizumab-treated patients $(0.3$ and $0.5 \mathrm{mg}$, respectively) lost $<15$ letters of visual acuity compared with $64 \%$ of photodynamic therapy-treated patients in month 12 (Brown et $\mathrm{al}^{4 \mathrm{bb}}$ ). Of the ranibizumab-treated patients, 36\% and $40 \%$ ( 0.3 and $0.5 \mathrm{mg}$, respectively) gained $\geqslant 15$ letters compared with $6 \%$ of photodynamic therapy-treated patients, a significant difference (Brown et $a l^{4 \mathrm{bb}}$ ).

Serious ocular adverse events were rare for both pegapta$\mathrm{nib}^{42}$ and ranibizumab (Rosenfeld et $a l^{41 \mathrm{a} a}$; Brown et $^{\mathrm{a} l^{4 \mathrm{~b}}}$ ), and were predominantly related to the ITV injection procedure itself, including presumed endophthalmitis, traumatic lens injury and retinal detachment. ${ }^{42}$ Serious uveitis occurred at a rate of $0-1 \%$ in pegaptanib-treated patients in the VISION trial, and at a rate of $0.7-0.8 \%$ in ranibizumab-treated 

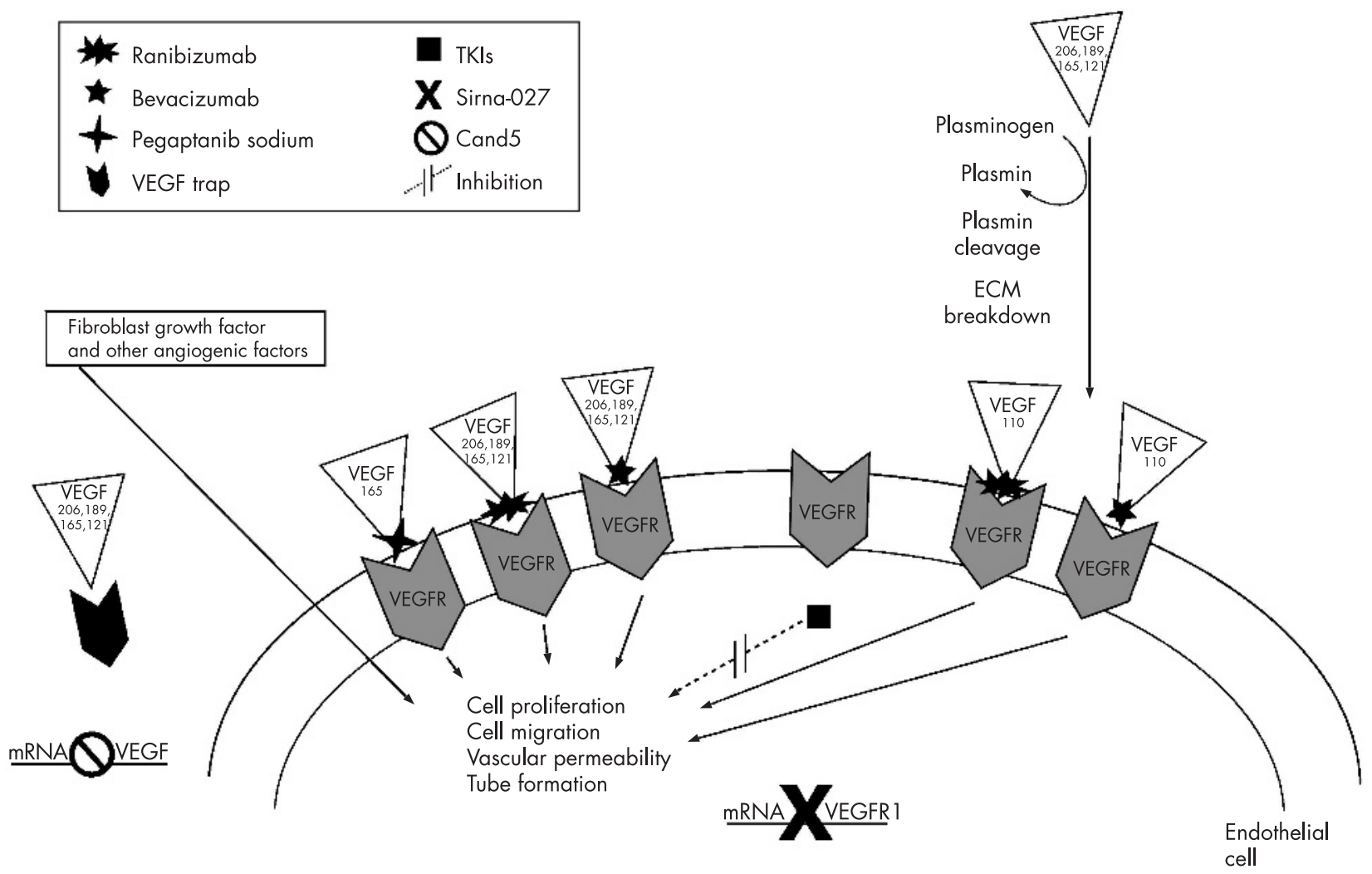

Figure 2 Key angiogenesis activators and inhibitors. Note that only the four major vascular endothelial growth factor (VEGF)-A isoforms are depicted in this schematic representation. ECM, extracellular matrix; TKIs, tyrosine kinase inhibitors; VEGFR, vascular endothelial growth factor receptor.

patients in the MARINA and ANCHOR trials (Rosenfeld et $a l^{41 a} ;$ Brown et $\left.a l^{41 b}\right)$. There is a theoretical possibility of untoward effects with long-term VEGF-A inhibition, particularly on normal choroidal and retinal vasculature. However, such toxicities have not been observed to this point in human clinical trials of ocular anti-VEGF treatments.

\section{SYSTEMIC RISKS WITH VEGF-A INHIBITION Intravenous infusion}

For patients with cancer, adjuvant bevacizumab treatment in phase III clinical trials improves median survival in patients with metastatic colorectal cancer $(\mathrm{CRC})^{60}$ and improves response rate (but not progression-free survival) in patients with metastatic breast cancer. ${ }^{61}$ In these patients with latestage cancer receiving serial intravenous infusion of bevacizumab at doses of $5-15 \mathrm{mg} / \mathrm{kg}$, there were increased risks of systemic adverse events. Compared with chemotherapy alone, bevacizumab in combination with chemotherapy is associated with an increased incidence of hypertension, bleeding and proteinuria in patients with $\mathrm{CRC}^{62}$ and an increased rate of thromboembolic events, gastrointestinal perforations, myocardial infarction and death in patients with breast cancer and CRC. ${ }^{61}{ }^{62}$

A different serious adverse-event profile has been seen in the limited number of patients without cancer studied with intravenous bevacizumab used as monotherapy. In a small study of off-label intravenous infusion of bevacizumab in patients with AMD, seven of nine patients experienced hypertension controllable with drugs, but no serious ocular or systemic adverse events were reported. ${ }^{63}$ Similarly, no ocular or systemic adverse events were reported in two patients with pathological myopia treated off-label with intravenous infusion of bevacizumab. ${ }^{64}$

\section{Intravitreal administration}

Given the risks of intravenous adjuvant bevacizumab treatment seen in patients with cancer, systemic risks also theoretically exist with ITV administration of anti-VEGF treatments. Although the dosages in ocular therapy are several orders of magnitude lower, ITV injection does lead to detectable levels in the serum. In monkeys the vitreous half life $\left(t_{1 / 2}\right)$ of ranibizumab is 3 days, and after ITV injection of $0.5 \mathrm{mg}$, the maximum serum level is $150 \mathrm{ng} / \mathrm{ml}$, with a serum half life of 3.5 days. ${ }^{65}$ In human studies, the mean (SD) serum concentration of ranibizumab $1 \mathrm{~h}$ after ITV administration $(0.3 \mathrm{mg})$ was 1.01 ( 1.35$) \mathrm{ng} / \mathrm{ml}$, and after 28 days serum concentrations were $<0.300 \mathrm{ng} / \mathrm{ml}$ in $96 \%$ of the patients. ${ }^{66}$ Such levels of serum ranibizumab are below the approximately $10 \mathrm{ng} / \mathrm{ml}$ threshold estimated to affect VEGFA-related activity in humans. ${ }^{66} 67$

The serum half life of pegaptanib after ITV administration ( $3 \mathrm{mg}$ ) in humans is 10 days, with a mean maximum serum concentration of pegaptanib of $80 \mathrm{ng} / \mathrm{ml} .{ }^{68}$ In contrast, the serum half life of the full-length anti-VEGF antibody bevacizumab is 17-21 days in humans; mABs tend to have relatively longer half lives than antigen-binding fragments. ${ }^{69}$

The various VEGF-A isoforms are distributed widely in tissue; theoretically, broad inhibition of VEGF-A isoforms confers higher non-specificity and systemic risk, as does prolonged serum half life. To date, more than 2000 patients have received serial ITV injections in the controlled clinical trials of pegaptanib and ranibizumab without showing increased risk of systemic adverse events for either agent. The systemic safety of ITV bevacizumab is not established, but no known serious adverse events have been reported in uncontrolled studies to date..$^{53} 7071$ As the clinical use of ITV VEGF inhibition expands, ongoing monitoring for systemic adverse events may be warranted. 


\section{CONCLUSIONS}

Anti-VEGF agents are the first biological compounds to be developed specifically for retinal therapeutics. The retinal community is currently dealing with aspects of these novel drugs in the management of patients with neovascular AMD. Unresolved clinical issues include: optimal injection frequency; duration of the treatment regimen; possible combination treatments; and potential applications for retinal diseases beyond AMD. In light of the role of VEGF-A in diverse organ systems in normal adults, long-term VEGF-A suppression raises theoretical ocular and systemic safety issues; however, no evidence of such increased risks has been observed in controlled clinical trials of pegaptanib or ranibizumab for patients with neovascular AMD. VEGF-A is perhaps the most widely researched molecule in ophthalmology; as such, VEGF science may be valuable to doctors in refining the clinical application of this new class of drugs.

\section{ACKNOWLEDGEMENTS}

This project was supported by "That Man May See Foundation". Writing and research assistance was supported by Genentech.

Competing interests: None declared.

\section{REFERENCES}

1 Ferrara N, Gerber HP, LeCouter J. The biology of VEGF and its receptors. Nat Med 2003;9:669-76.

2 Senger DR, Galli SJ, Dvorak AM, et al. Tumor cells secrete a vascular permeability factor that promotes accumulation of ascites fluid. Science 1983;219:983-5.

3 Leung DW, Cachianes G, Kuang WJ, et al. Vascular endothelial growth factor is a secreted angiogenic mitogen. Science 1989;246:1306-9

4 Ferrara N, Henzel WJ. Pituitary follicular cells secrete a novel heparin-binding growth factor specific for vascular endothelial cells. Biochem Biophys Res Commun 1989;161:851-8.

5 Miyamoto K, Khosrof S, Bursell SE, et al. Vascular endothelial growth factor (VEGF)-induced retinal vascular permeability is mediated by intercellular adhesion molecule-1 (ICAM-1). Am J Pathol 2000;156:1733-9.

6 Azzouz M, Ralph GS, Storkebaum E, et al. VEGF delivery with retrogradely transported lentivector prolongs survival in a mouse ALS model. Nature 2004:429:413-17.

7 Ding XM, Mao BY, Jiang S, et al. Neuroprotective effect of exogenous vascular endothelial growth factor on rat spinal cord neurons in vitro hypoxia. Chin Med J (Engl), 2005; 118:1644-50.

8 Karkkainen MJ, Makinen T, Alitalo K. Lymphatic endothelium: a new frontier of metastasis research. Nat Cell Biol 2002;4:E2-5.

9 Olofsson B, Korpelainen E, Pepper MS, et al. Vascular endothelial growth factor B (VEGF-B) binds to VEGF receptor-1 and regulates plasminogen activator activity in endothelial cells. Proc Natl Acad Sci USA 1998:95:11709-14.

10 Baver SM, Baver RJ, Liu Z, et al. Vascular endothelial growth factor-C promotes vasculogenesis, angiogenesis, and collagen constriction in threedimensional collagen gels. J Vasc Surg 2005:41:699-707.

11 Carmeliet P, Ferreira V, Breier G, et al. Abnormal blood vessel development and lethality in embryos lacking a single VEGF allele. Nature 1996;380:435-9.

12 Ferrara N. Role of vascular endothelial growth factor in physiologic and pathologic angiogenesis: therapeutic implications. Semin Oncol 2002;29:10-14.

13 Yonekura H, Sakurai S, Liu X, et al. Placenta growth factor and vascular endothelial growth factor $B$ and $C$ expression in microvascular endothelial cells and pericytes. Implication in autocrine and paracrine regulation of angiogenesis. J Biol Chem 1999;274:35172-8.

14 Stacker SA, Caesar C, Baldwin ME, et al. VEGF-D promotes the metastatic spread of tumor cells via the lymphatics. Nat Med 2001;7:186-91.

15 Takahashi H, Shibuya M. The vascular endothelial growth factor (VEGF)/ VEGF receptor system and its role under physiological and pathological conditions. Clin Sci (Lond), 2005;109:227-41

16 Lee JH, Canny MD, De Erkenez A, et al. A therapeutic aptamer inhibits angiogenesis by specifically targeting the heparin binding domain of VEGF165. Proc Natl Acad Sci USA 2005;102:18902-7.

17 Houck KA, Leung DW, Rowland AM, et al. Dual regulation of vascular endothelial growth factor bioavailability by genetic and proteolytic mechanisms. J Biol Chem 1992;267:26031-7.

18 Park JE, Keller GA, Ferrara N. The vascular endothelial growth factor (VEGF) isoforms: differential deposition into the subepithelial extracellular matrix and bioactivity of extracellular matrix-bound VEGF. Mol Biol Cell 1993:4:1317-26.

19 Keyt BA, Berleau LT, Nguyen HV, et al. The carboxyl-terminal domain (111$165)$ of vascular endothelial growth factor is critical for its mitogenic potency. J Biol Chem 1996;271:7788-95.
20 Soker S, Takashima S, Miao HQ, et al. Neuropilin-1 is expressed by endothelial and tumor cells as an isoform-specific receptor for vascular endothelial growth factor. Cell 1998;92:735-45.

21 Zhang HT, Scott PA, Morbidelli L, et al. The 121 amino acid isoform of vascular endothelial growth factor is more strongly tumorigenic than other splice variants in vivo. Br J Cancer 2000;83:63-8

22 Fairbrother WJ, Champe MA, Christinger HW, et al. Solution structure of the heparin-binding domain of vascular endothelial growth factor. Structure 1998;6:637-48

$23 \mathrm{Ng}$ YS, Rohan R, Sunday ME, et al. Differential expression of VEGF isoforms in mouse during development and in the adult. Dev Dyn 2001;220:112-21.

24 Gogat K, Le Gat L, Van Den Berghe L, et al. VEGF and KDR gene expression during human embryonic and fetal eye development. Invest Ophthalmol Vis Sci 2004;45:7-14

25 Demir R, Kayisli UA, Cayli S, et al. Sequential steps during vasculogenesis and angiogenesis in the very early human placenta. Placenta 2006;27:535-9.

26 Meeson AP, Argilla M, Ko K, et al. VEGF deprivation-induced apoptosis is a component of programmed capillary regression. Development 1999; 126:1407-15.

27 Gordon JD, Mesiano S, Zaloudek CJ, et al. Vascular endothelial growth factor localization in human ovary and fallopian tubes: possible role in reproductive function and ovarian cyst formation. J Clin Endocrinol Metab 1996;81:353-9.

28 Gerber HP, Hillan KJ, Ryan AM, et al. VEGF is required for growth and survival in neonatal mice. Development 1999;126:1149-59.

29 Martin AC, Thornton JD, Liu J, et al. Pathogenesis of persistent hyperplastic primary vitreous in mice lacking the arf tumor suppressor gene. Invest Ophthalmol Vis Sci 2004;45:3387-96.

30 Marneros AG, Fan J, Yokoyama Y, et al. Vascular endothelial growth factor expression in the retinal pigment epithelium is essential for choriocapillaris development and visual function. Am J Pathol 2005; 167:1451-9.

31 Stone J, Itin A, Alon T, et al. Development of retinal vasculature is mediated by hypoxia-induced vascular endothelial growth factor (VEGF) expression by neuroglia. J Neurosci 1995; 15:4738-47.

32 Gerhardt $H$, Golding $M$, Fruttiger $M$, et al. VEGF guides angiogenic sprouting utilizing endothelial tip cell filopodia. J Cell Biol 2003;161:1163-77.

33 Murata T, Nakagawa K, Khalil A, et al. The temporal and spatial vascular endothelial growth factor expression in retinal vasculogenesis of rat neonates. Lab Invest 1996;74:68-77.

34 Stalmans I, Ng YS, Rohan R, et al. Arteriolar and venular patterning in retinas of mice selectively expressing VEGF isoforms. J Clin Invest 2002;109:327-36.

$35 \mathrm{McColm}$ JR, Geisen P, Hartnett ME. VEGF isoforms and their expression after a single episode of hypoxia or repeated fluctuations between hyperoxia and hypoxia: relevance to clinical ROP. Mol Vis 2004;10:512-20.

36 Jakeman LB, Winer J, Bennett GL, et al. Binding sites for vascular endothelia growth factor are localized on endothelial cells in adult rat tissues. J Clin Invest 1992;89:244-53.

37 Baffert F, Le T, Sennino B, et al. Cellular changes in normal blood capillaries undergoing regression after inhibition of VEGF signaling. Am J Physiol Heart Circ Physiol 2006;290:H547-59.

38 Kasahara Y, Tuder RM, Taraseviciene-Stewart L, et al. Inhibition of VEGF receptors causes lung cell apoptosis and emphysema. J Clin Invest 2000;106:1311-19.

39 Blaauwgeers HG, Holtkamp GM, Rutten $\mathrm{H}$, et al. Polarized vascular endothelial growth factor secretion by human retinal pigment epithelium and localization of vascular endothelial growth factor receptors on the inner choriocapillaris. Evidence for a trophic paracrine relation. Am J Pathol 1999:155:421-8.

40 Kim I, Ryan AM, Rohan R, et al. Constitutive expression of VEGF, VEGFR-1, and VEGFR-2 in normal eyes. Invest Ophthalmol Vis Sci 1999;40:21 15-21.

41 Ozaki H, Seo MS, Ozaki K, et al. Blockade of vascular endothelial cell growth factor receptor signaling is sufficient to completely prevent retinal neovascularization. Am J Pathol 2000;156:697-707.

4 la Rosenfeld P, Brown DM, Heier JS, et al. Ranibizumab for neovascular agerelated macular degeneration. N Engl J Med 2006;355:1419-31.

41b Brown DM, Kaiser PK, Michels $M$, et al. Ranibizumab versus verteporfin for neovascular age-related macular degeneration. $N$ Engl J Med 2006;355: 1432-44.

42 Gragoudas ES, Adamis AP, Cunningham Jr ET, et al. Pegaptanib for neovascular age-related macular degeneration. $N$ Engl J Med 2004:351:2805-16.

43 Rakic JM, Lambert V, Devy L, et al. Placental growth factor, a member of the VEGF family, contributes to the development of choroidal neovascularization. Invest Ophthalmol Vis Sci 2003:44:3186-93.

44 Aiello LP, Avery RL, Arrigg PG, et al. Vascular endothelial growth factor in ocular fluid of patients with diabetic retinopathy and other retinal disorders. N Engl J Med 1994;331:1480-7.

45 Boyd SR, Zachary I, Chakravarthy U, et al. Correlation of increased vascular endothelial growth factor with neovascularization and permeability in ischemic central vein occlusion. Arch Ophthalmol 2002;120:1644-50.

46 Noma H, Minamoto A, Funatsu H, et al. Intravitreal levels of vascular endothelial growth factor and interleukin-6 are correlated with macular edema in branch retinal vein occlusion. Graefes Arch Clin Exp Ophthalmol 2006;244:309-15

47 Kvanta A, Algvere PV, Berglin L, et al. Subfoveal fibrovascular membranes in age-related macular degeneration express vascular endothelial growth factor. Invest Ophthalmol Vis Sci 1996;37:1929-34.

48 Adamis AP, Miller JW, Bernal MT, et al. Increased vascular endothelial growth factor levels in the vitreous of eyes with proliferative diabetic retinopathy. Am J Ophthalmol 1994;118:445-50. 
49 Usui T, Ishida S, Yamashiro K, et al. VEGF164(165) as the pathological isoform: differential leukocyte and endothelial responses through VEGFR1 and VEGFR2. Invest Ophthalmol Vis Sci 2004;45:368-74.

50 Ishida S, Usui T, Yamashiro K, et al. VEGF164 is proinflammatory in the diabetic retina. Invest Ophthalmol Vis Sci 2003:44:2155-62.

51 Shima DT, Gougos A, Miller JW, et al. Cloning and mRNA expression of vascular endothelial growth factor in ischemic retinas of Macaca fascicularis. Invest Ophthalmol Vis Sci 1996;37:1334-40.

52 Akiyama H, Mohamedali K, Lima-Silva R, et al. Vascular targeting of ocular neovascularization with a VEGF121/gelonin chimeric protein. Mol Pharmacol 2005;68: 1543-50.

53 Avery RL, Pieramici DJ, Rabena MD, et al. Intravitreal bevacizumab (Avastin) for neovascular age-related macular degeneration. Ophthalmology 2006;113:363-72

54 Rosenfeld PJ, Moshfeghi AA, Puliafito CA. Optical coherence tomography findings after an intravitreal injection of bevacizumab (Avastin ${ }^{\circledR}$ ) for neovascular age-related macular degeneration. Ophthalmic Surg Lasers Imaging 2005;36:331-5.

55 Konner J, Dupont J. Use of soluble recombinant decoy receptor vascular endothelial growth factor trap (VEGF trap) to inhibit vascular endothelial growth factor activity. Clin Colorectal Cancer 2004;4(Suppl 2):S81-5.

56 Maier P, Unsoeld AS, Junker B, et al. Intravitreal injection of specific receptor tyrosine kinase inhibitor PTK787/ZK222 584 improves ischemia-induced retinopathy in mice. Graefe's Arch Clin Exp Ophthalmol 2005;243:593-600.

57 Reich SJ, Fosnot J, Kuroki A, et al. Small interfering RNA (siRNA) targeting VEGF effectively inhibits ocular neovascularization in a mouse model. Mol Vis 2003:9:210-16.

58 Gonzales CR. Enhanced efficacy associated with early treatment of neovascular age-related macular degeneration with pegaptanib sodium: an exploratory analysis. Retina 2005;25:815-27.

59 Cunningham ET Jr, Adamis AP, Altaweel M, et al. A phase II randomized double-masked trial of pegaptanib, an anti-vascular endothelial growth factor aptamer, for diabetic macular edema. Ophthalmology 2005;1 12:1747-57.

60 Hurwitz HI, Fehrenbacher L, Hainsworth JD, et al. Bevacizumab in combination with fluorouracil and leucovorin: an active regimen for first-line metastatic colorectal cancer. J Clin Oncol 2005;23:3502-8.
61 Miller KD, Chap LI, Holmes FA, et al. Randomized phase III trial of capecitabine compared with bevacizumab plus capecitabine in patients with previously treated metastatic breast cancer. J Clin Oncol 2005;23:792-9.

62 Hurwitz H, Fehrenbacher L, Novotny W, et al. Bevacizumab plus irinotecan, fluorouracil, and leucovorin for metastatic colorectal cancer. N Engl J Med 2004; 350:2335-42.

63 Michels S, Rosenfeld PJ, Puliafito CA, et al. Systemic bevacizumab (Avastin) therapy for neovascular age-related macular degeneration twelve-week results of an uncontrolled open-label clinical study. Ophthalmology 2005; 112:1035-47.

64 Nguyen QD, Shah S, Tatlipinar S, et al. Bevacizumab suppresses choroidal neovascularisation caused by pathological myopia. $\mathrm{Br} J$ Ophthalmol 2005;89:1368-70

65 Gaudreault J, Fei D, Rusit J, et al. Preclinical pharmacokinetics of ranibizumab (rhuFabV2) after a single intravitreal administration. Invest Ophthalmol Vis Sci 2005;46:726-33.

66 Haughney PC, Lowe J, Kearns, et al. Clinical pharmacokinetics of ranibizumab (Lucentis ${ }^{\text {TMM }}$ ) in subjects with AMD. Presented at 2005 ARVO Annual Meeting,Fort Lauderdale, FL, USA. May, 2005: 1-5

67 Rosenfeld PJ, Schwartz SD, Blumenkranz MS, et al. Maximum tolerated dose of a humanized anti-vascular endothelial growth factor antibody fragment for treating neovascular age-related macular degeneration. Ophthalmology 2005; 1 12:1048-53.

68 Siddiqui MA, Keating GM. Pegaptanib: in exudative age-related macular degeneration. Drugs 2005;65:1571-7.

69 Hudson PJ, Souriau C. Engineered antibodies. Nat Med 2003;9:129-34.

70 Rosenfeld PJ, Fung AE, Puliafito CA. Optical coherence tomography findings after an intravitreal injection of bevacizumab (Avastin) for macular edema from central retinal vein occlusion. Ophthalmic Surg Lasers Imaging 2005;36:336-9.

71 Fung AE, Rosenfeld PJ, Reichel E. The International Intravitreal Bevacizumab Safety Survey: using the internet to assess drug safety worldwide. $\mathrm{Br} J$ Ophthalmol 2006;90:1344-9. 